\title{
MARÍA ARACIL Y SACHA SAVAROF: DOS PROTAGONISTAS BAROJIANAS
}

\author{
Eva Orts Agulló \\ (Universidad de Córdoba) \\ evaorts@hotmail.com
}

RESUMEN: Pío Baroja ha sido considerado por la crítica como un hombre misógino y un escritor que no se ha detenido en los personajes femeninos. Este artículo pretende destacar el importante papel de dos figuras femeninas que son, además, protagonistas de tres novelas. Estas heroínas no son figuras estáticas sino que, como los demás héroes barojianos, van rodando de un lugar a otro. Baroja dedica los primeros capítulos para explicar cómo el medio en el que crecen determina su personalidad y, en la elaboración de la joven estudiante de Medicina Sacha Savarof, se observa la influencia de Schopenhauer. En las novelas aparecen temas de interés para la mujer como la educación, la amistad femenina o el divorcio, lo que sitúa el pensamiento barojiano en la vanguardia del feminismo.

PALABRAS ClAVE: Baroja, Misoginia, Personajes femeninos, Schopenhauer, Feminismo.

\section{MARÍA ARACIL AND SACHA SAVAROF: TWO FEMALE CHARACTERS IN PÍO BAROJA'S NARRATIVE}

ABSTRACT: Pío Baroja has been considered by critics as a misogynist and a writer who has not created valuable female characters. This article aims to highlight the importance of the roles of two female figures who are also protagonists of three of his novels. These heroines are not static figures but, like the author's other heroes, they move from one place to another. Baroja dedicates the first chapters to explain how the environment in which they grow determines their personality and, in the development of the young medical student Sacha Savarof, Schopenhauer's influence is observed. In the novels appear topics of interest for women such as education, female friendship or divorce; what places Baroja's thought at the forefront of feminism.

KEYWORDS: Baroja, Misogyny, Female characters, Schopenhauer, Feminism.

Baroja es un escritor que ha tenido y tiene un público fiel. Entre los lectores destaca el gran número de mujeres que lo han seguido desde sus inicios. Esto puede resultar sorprendente teniendo en cuenta la fama de misógino que le ha acompañado durante años. ${ }^{1}$ Asimismo, se ha llegado a afirmar que no aparece ninguna auténtica

${ }^{1}$ Bergasa (1973: 360) afirma: «No tiene, ciertamente, Baroja demasiada buena opinión de las mujeres. Espigando su obra, resulta, al menos, muy difícil, por no decir casi imposible, hallar un comentario, un juicio, una alusión que pueda, genéricamente, serles del todo favorable». Elizade (1975: 175) remarca que es «proverbial» la hostilidad de Baroja hacia lo femenino: «El hecho de ser discípulo de Schopenhauer y de Niestzsche y la frustración amorosa en su vida constituyen, en parte, una razón de su misoginia». Este tipo de afirmaciones penetraron en los manuales de literatura propagándose la idea de su aversión por las mujeres, así, en el de Lázaro y Tusón se apuntaba en el apartado Vida y personalidad de Pío Baroja: «sabido es que su timidez y su espíritu de independencia, más aún que su misoginia, le hicieron rechazar el matrimonio, a la vez que fustigaba el recurso de la prostitución; optó por una auto- 
mujer en sus obras (Elizalde, 1975: 8) y que el novelista pasa «por sus personajes femeninos sin detenerse, con la prisa de quien quisiera terminar cuanto antes el retrato recién abocetado» (Bergasa, 1973: 303). ${ }^{2}$ Sin embargo, dichas aseveraciones no siempre han ido acompañadas de una investigación exhaustiva de su novelística. Ignacio Elizade únicamente dedica un capítulo de su libro Personajes y temas barojianos (1975) al estudio de la mujer vasca y Bergasa en Baroja, las mujeres y el sexo (1973) consagra una parte, de las seis que contiene su obra, a la mujer como personaje. No obstante, recientemente, han salido a la luz nuevos análisis que aportan datos diferentes sobre este tema tan poco investigado. Así, en el 2003 apareció el artículo de Virginia Trueba «Lulú: el extraño personaje de El árbol de la ciencia de Pío Baroja» donde rebate la escueta descripción que Ortega hizo de Lulú, quien para la autora es «figura de primer orden para el entendimiento de la novela» (Trueba, 2003: 186). ${ }^{3}$ Encontramos, también, el artículo de Katherine Murphy «The Female Subject in Pío Baroja: Sexual Ideology and the New Woman in El árbol de la ciencia and El mundo es ansí» (2012) quien asegura que las mujeres no están en los márgenes del texto, sino que «are in fact central to the philosophical, ideological, and narratological concerns of his fiction» (Murphy, 2012: 1002). Igualmente, en el recientemente publicado libro de Ascensión Rivas, Mujeres barojianas (2017), la autora se pregunta cómo se ha podido aceptar que los personajes femeninos sean planos y carezcan de profundidad, a la vez que expresa su asombro ante el desmesurado interés por la misoginia barojiana «sobre todo porque nunca he creído en ella» (Rivas, 2017: 26, 22).

Resulta conmovedor que hayan sido mujeres académicas las que se han interesado en deshacer la peyorativa asunción de la misoginia barojiana y destacar el importante papel de las figuras femeninas en su obra. ${ }^{4}$ La crítica feminista sugiere que los académicos de mediados del siglo XX, al elaborar el canon de la ficción española anterior a la Guerra Civil, menospreciaron los textos «centered on the exploration of female experience» (Bieder, 1992: 301).Comentarios como el de Elizade (1975: 175) lo ejemplifican muy bien: «El lector recordará sin esfuerzo los nombres de Santhi Andía, Avinareta o Zalacaín, pero no a la compañera de sus vidas. Ninguna de las mujeres barojianas han pasado a la historia de las grandes figuras femeninas de nuestra novelística». El interés de este artículo es, por tanto, contribuir a aportar un poco de luz sobre el papel de estas mujeres que tan poca atención crítica han recibido dentro de la narrativa de Pío Baroja. El punto de partida es analizar, utilizando los instrumentos de la narratología, la construcción de dos personajes femeninos que son, además, protagonistas de tres novelas de su primera etapa: María Aracil en La dama errante (1908) y en La ciudad de la niebla (1909) y Sacha V. Savarof en El mundo es ansí (1912).

represión a la que atribuye él mismo un "desequilibrio" y un talante de "hombre rabioso"» (Lázaro y Tusón, 1990: 68).

${ }^{2}$ Francisco Umbral (1999) también señaló la ausencia de mujeres en su obra: «en sus novelas falta la mujer» y aludió a su misoginia: «A Baroja, misógino, le invitaban mucho las marquesas...».

${ }^{3}$ Andrés Hurtado «se une en matrimonio con una extraña y simpática mujercita» son las únicas palabras que le dedicó Ortega a este personaje en su análisis de El árbol de la ciencia (Trueba: 2003, 183).

${ }^{4}$ José-Carlos Mainer (2012: 207-209) señala que al ensayista hispanoargentino Juan Mas y Pi «le han interesado, sobre todo las mujeres de Baroja» en un análisis que realizó sobre su obra en Letras españolas publicada en 1911 (volumen poco citado). También indica que en 1928 Francisco Pina Brotons, un joven periodista oriolano, en el libro Pío Baroja «rebatió la imputación de misoginia que se le hacía tan frecuentemente» (2012: 274-275). No obstante, Mainer, autor de esta reciente biografía de Baroja, aún eximiéndole, continúa considerando este lugar común barojiano al apuntar que su misoginia es «muy venial, en todo caso» (2012: 32 ). 
MARÍA ARACIL

Ocho años después de estrenarse como autor literario con Vidas sombrías (1900), Baroja elige a una mujer como protagonista de las dos primeras partes de la trilogía «La raza»: La dama errante ${ }^{5}$ y La ciudad de la niebla. ${ }^{6}$ Estas dos novelas forman una unidad entre sí que se distancia casi completamente de El árbol de la ciencia (1911), haciéndose coincidir únicamente a un personaje, el doctor Iturrioz.

María Aracil es una joven burguesa madrileña inspirada en un modelo real que, como Baroja asegura en el prólogo a la edición de 1914 de La dama errante: ${ }^{7}$ «pasea por las mañanas por la calle de Alcalá» $(13-14) .{ }^{8}$ Con esto, el escritor acredita como verdadero el carácter de su protagonista, aunque en la novela forme parte de un mundo ficcional. Lo destacable de este personaje es que a diferencia de las grandes heroínas de los autores realistas o naturalistas donde la mujer es esencialmente una figura estática (Bieder, 1992: 303), Baroja fuerza a su heroína a iniciar un periplo por España y Portugal al verse comprometida a huir a Londres con su padre como refugiada política. Resulta sorprendente, por tanto, que cuando Elizade (1975: 36) señale que el prototipo del personaje barojiano es el trotamundos, no cite a María Aracil, cuyo viaje sobrepasa la frontera española y, sin embargo, nombre a Fernando Ossorio, de Camino de Perfección y a Andrés Hurtado, de El árbol de la ciencia, cuyos desplazamientos se limitan al interior de la península.

María es una muchacha poco común y, como muchos personajes barojianos, encarna rasgos propios del autor como el individualismo, la sinceridad y una personalidad fuerte. El escritor nos la presenta a través de un narrador heterodiegético y omnisciente que dedica los dos primeros capítulos de La dama errante a explicar cómo el excepcional hábitat en el que se crio de niña determinó que desarrollara un carácter diferente al del resto de las mujeres. De esta manera, Baroja retoma la idea del medio ambiente como configurador de la personalidad que ya había utilizado en la trilogía anterior «La lucha por la vida». ${ }^{9}$

En primer lugar es decisiva la situación de abandono que rodeó a María desde niña: huérfana de madre, sin mucha atención por parte de su padre, únicamente la abuela se encargó de cuidarla hasta los siete años, y gracias a ello, «pudo tener ideas de niña y vida de niña» (20). Para el narrador este es uno de los factores que explican la singular personalidad de este personaje porque: «en nuestra época y en nuestro país es muy difícil ser niño. [...] La mayoría de los hombres y de las mujeres no han vivido nunca la niñez. [...] El padre, la madre, el criado, el profesor, la institutriz, el municipal, todos conspiran contra la infancia» (19). Este aislamiento con respecto a la familia — «María no conoció a sus tías y primas hasta los catorce o quince años» (26)—, la

${ }^{5}$ Aunque parece obvio que La dama errante está titulada en referencia a su protagonista María Aracil, Mainer (2012: 161-162) señala que el protagonista es su padre, el doctor Enrique Aracil y María no es más que «un personaje aparentemente secundario pero, sin embargo, fundamental».

6 «La dama errante y La ciudad de la niebla tienen como telón de fondo histórico el atentado frustrado del anarquista catalán Mateo Morral contra Alfonso XIII, el día de su boda con Victoria Eugenia, sobrina del rey británico Eduardo VII. Al paso de la comitiva por la calle Mayor de Madrid, el 31 de mayo de 1906, mateo Morral lanzó una bomba envuelta en un ramo de flores que provocó veintitrés muertos y un centenar de heridos, pero no la muerte de los reyes» (Orts, 2017: 153).

${ }^{7}$ Todas las citas de la novela corresponden a la edición: La dama errante, Madrid, Caro Raggio, 1995. A partir de ahora se citará indicando solo el número de página que corresponda.

${ }^{8}$ Jorge Campos (1981: 86) apunta que el periodista republicano José Nakens y su hija son las personas reales en las que se inspiró Baroja cuando concibió al doctor Aracil y a su hija.

${ }^{9}$ Baroja utiliza conceptos y planteamientos procedentes de la teoría científica de Darwin descrita en El origen de las especies (1859) para construir sus personajes. Véase mi estudio Personaje y espacio urbano en la narrativa de Pío Baroja, 2017: 45, 55. 
escuela y la religión — «A los diez años, María ni sabía leer ni había puesto los pies en la iglesia» (25) - justifican que tenga un comportamiento y una manera de pensar diferente al de las muchachas de su edad que: «vivían desde los trece a catorce años una vida inmoral, subordinando todos sus planes al marido futuro [...], dedicándose a la caza legal del macho, sin pensar que podían tener una vida suya, propia, independiente de la eventualidad del matrimonio» (26). En La dama errante las primas de María serán su contrapunto al representar el papel de la mujer tradicional impuesto por la sociedad (Trueba, 2003: 187); ${ }^{10}$ en La ciudad de la niebla lo serán las señoras del hotel. ${ }^{11}$

En segundo lugar, María comienza su formación a los diez años «cuando le vino el deseo de aprender» (25). Su padre contrata entonces a una institutriz «buena y cariñosa, que enseñó a María a leer y a escribir, algunas nociones de Matemáticas y el inglés y el francés perfectamente» (25). En Juventud, egolatría Baroja (1977: 68) destaca la importancia de poseer una biblioteca entre los doce y los veinte años porque es la «época que a mí me parece más trascendental para la formación del espíritu». María, en su casa, tiene acceso a los libros de la biblioteca del doctor: «Leyó desde Heródoto hasta Nansen, y estas lecturas serenas, unidas a su falta absoluta de ideas religiosas, le permitieron poder pasear la mirada por encima de las doctrinas y de los hechos, sin turbación alguna» (32). Resulta muy significativo para la caracterización psicológica de María que se interese por los libros de grandes viajeros, como el explorador noruego Nansen y que, más adelante, cuando entable amistad con su primo Venancio, este le preste los libros de aventuras de Julio Verne, ya que casi todos son de viajes. ${ }^{12}$ Esta preparación intelectual y moral, sin embargo, no hubiera tenido lugar de haber asistido a la escuela. Venancio describe cómo es la educación que reciben las niñas en España:

Entre el miedo al diablo, el hacer trabajar la inteligencia sobre el vacío de estúpidas abstracciones y la falta de ejercicio, los colegios españoles estropean la raza. No dan más que dos productos, y los dos malos: la mujercita histérica, mística y desquiciada, o la mujerona gorda y bestial (50).

El narrador utiliza adjetivos como «infeccioso» y «crudo» para describir el ambiente en el que se desarrollan las mujeres españolas. Estas viven bajo la presión de una cultura donde «el sentimiento de categoría social, unido al del pecado, enfermaba a estas mujeres el alma» (29). En sus memorias, Baroja (2006: 378) lamenta que las mujeres «no pensaban en el matrimonio más que como una carrera» por ello, en la

${ }^{10}$ Así, para las primas de María: «La perspectiva soñada del marido rico les impedía realizar los actos más sencillos, de miedo a la opinión ajena» (26). María, sin embargo, no duda en ir a visitar, siempre que puede a su primo Venancio, un geólogo viudo, padre de cuatro niñas, a pesar de que en la época estuviera mal visto que una mujer fuera sola a la casa de un hombre. El individualismo de María es consecuentemente censurado por su tía Belén: «Chica, eso no se puede hacer [...] ¿Qué va a decir la gente?» (55).

${ }^{11}$ Baroja señala la nobleza de María que acude a diario a visitar a su criada enferma, conducta considerada de mal gusto por el resto de las mujeres alojadas en el hotel. Este pequeño detalle se utiliza para criticar una moral basada en la hipocresía: «a estas damas les parecía bien, hasta elegante, el visitar a los enfermos pobres siempre que se perteneciese a una Junta benéfica de señoras presidida por alguna duquesa, o por lo menos por una lady, y se realizaran las visitas con cierto aparato, entre mundano y de solemnidad religiosa» (26). Todas las citas de la novela corresponden a la edición La ciudad de la niebla, Madrid, Caro Raggio, 1974. A partir de ahora se citará indicando solo el número de página. En La Busca ya había censurado a las marquesas que acudían con sus biblias a las barriadas del Manzanares «un simulacro de caridad, que no remediaba nada» (1997b: 92).

${ }^{12}$ Cinco semanas en globo (1863), 20.000 leguas de viaje submarino (1869), La vuelta al mundo en 80 días (1873). 
ficción, elabora esta figura femenina que «quería llegar a vivir independiente, para ella, sin hacer alarde de su independencia; al revés, ocultándola como un defecto» (30).

María es también una mujer de acción: enérgica, decidida y resolutiva, mientras que su padre, hombre de éxito en Madrid, ${ }^{13}$ en la adversidad resulta timorato, cobarde y débil «era pusilánime como un niño enfermo» (101). Cuando Aracil le cuente a su hija que su protegido, Nilo Brull, ha sido el autor del atentado contra los reyes, esta toma las riendas de la historia y va proponiendo todos los pasos a seguir:

- Hay que huir y disfrazarse... Córtate la barba y el pelo; yo te lo cortaré.

Aracil sacó de un estuche unas tijeras y se sentó en la silla, sumiso como un niño. María recortó el pelo a su padre.

-Ahora, lo mejor sería que te afeitaras.

Aracil se dispuso a afeitarse (97).

Durante el viaje, el narrador va diseminando rasgos de la personalidad de la protagonista, siempre en contraste con los de su padre. En el final de La dama errante se observa claramente esta división de caracteres:

En medio de las tinieblas, de este abismo caótico de agua y de sombra, María respira con fuerza y se siente segura y tranquila. [...]

María respira como un hálito de vigor, de energía, al sentirse volar como una flecha en medio de la oscuridad y de las olas.

Vuelve a la cámara, en donde se ha refugiado su padre; las luces eléctricas, colgadas del techo oscilan suavemente. Aracil, pálido, demacrado, envuelto en una manta, con la cabeza más baja que los pies, permanece inmóvil.

- Mañana - dice María- estaremos en Londres.

Y Aracil, postrado por el mareo, hace un gesto de indiferencia (231-232).

Al distanciar a María de las características de la mujer tradicional (débil, dependiente, cobarde) y atribuírselas a su padre, Baroja muestra que estas no tienen por qué identificarse con el sexo femenino. Apartada de los estereotipos María se convierte en una mujer con voz propia en la primera parte de La ciudad de la niebla, al continuar en primera persona con el relato. En una narración que está a medio camino entre el diario íntimo y el libro de viajes, María describe y nos cuenta sus impresiones de la ciudad, así como sus planes para sobrevivir. Padre e hija buscan modos muy distintos de ganarse la vida, lo que será la trama principal de La ciudad de la niebla. Mientras que María decide perfeccionar su inglés y trabajar «seguir el camino recto: trabajando, luchando, sin buscar el atajo que pudiera llevar a la riqueza o al placer, próximos a la indignidad» (124), su padre elige «el camino tortuoso»: casarse por interés con una señora argentina rica y abandonar Europa.

En la segunda parte, Baroja introduce un asunto poco común en las obras de ficción escritas hasta el momento: el tema de la amistad femenina. El autor se hace cargo de la narración y María es presentada como amiga de dos mujeres, la noruega Wanda Rutney y la rusa Natalia Leskov —y no como la hija de Enrique Aracil o la

13 Baroja, en el capítulo segundo «El hombre bajo la máscara» da a conocer cómo es moralmente: «En realidad, el doctor presentaba todos los caracteres de un hombre de lujo, más superficial que hondo, más ingenioso que original y más cuco que sincero. [...] Sentía el buen doctor una egolatría fundamental, esas tan generales entre los cómicos, los profesores, los cantantes, los literatos y demás gente de perversa índole» (34-35). El escritor (2010: 17) recrea en Aracil un tipo habitual de la época, el charlatán de academia: «Hay varias clases de charlatanes; los hay de academia y de mitin, de calle y de plazuela; unos fijos y otros ambulantes, unos de lugar cerrado y otros de aire libre. Los de academia, de mitin y de lugar cerrado no me interesan nada». 
amante de un hombre-.Virginia Woolf, veinte años después de la publicación de $L a$ ciudad de la niebla, aún lamentaba esta ausencia en el conjunto de las producciones literarias:

Todas las relaciones entre mujeres, pensé recorriendo rápidamente la espléndida galería de figuras femeninas, son demasiado sencillas. Se han dejado tantas cosas de lado, tantas cosas sin intentar. Y traté de recordar entre todas mis lecturas algún caso en que dos mujeres hubieran sido presentadas como amigas [...]. Pero casi sin excepción se describe a la mujer desde el punto de vista de su relación con hombres (Woolf, 1992: 113).

El escritor, consciente de que una de las figuras más destacadas de la literatura española era Dulcinea del Toboso «que no existe más que en la imaginación de un hombre» (2006: 82), nos muestra una María luchadora, independiente, que comparte piso con Natalia Leskov y busca trabajo sin descanso gracias al apoyo de sus nuevas compañeras: «Me alentaba en compañía de estas dos amigas el verlas pensando en vivir en línea recta, sin abdicar, sin recurrir a la indignidad ni a la mentira» (70). Como ya señalé en otro lugar (2017: 174) «estas muchachas nórdicas recuerdan a Brickman y Julia Nissen, las amigas danesas que Carmen Baroja hizo en París en 1906, cuando estuvo con su hermano Pío durante seis meses en una pensión para estudiantes que dirigía Madame Paulhan». No obstante, como se explica al principio de esta segunda parte titulada «Las desilusiones», la vida heroica que pretende María no es posible en el mundo industrializado. El narrador alude a la ingenuidad de la madrileña: «Nunca hubiera sospechado que la vida del trabajo tuviera tantas vejaciones y tanta amargura» (139). Tras ensayar varios empleos, acudirá durante algunos meses, con un horario de nueve a cinco, a una oficina de la City. El ambiente del despacho le resulta incómodo: «no se acostumbraba a estar tantas horas, quieta y encerrada, ni al frío, ni a la gente adusta y poco comunicativa» (183). Varios personajes destacan el esfuerzo de la española por vivir sola e independiente en la metrópolis oscura: Iturrioz señala que es «toda una heroína» (188) y el señor Roche le dirá: «Es usted un caso de valor, miss Aracil. [...] Juana de Arco a su lado me parece un niño de teta» (226). Finalmente, será la inclinación sentimental el «elemento perturbador y causa del fracaso» (Lee Bretz, 1979: 365). Sin embargo, esta derrota es justificada por Iturrioz:

Estamos aplastados por siglos de historia que caen sobre nuestros hombros como una losa de plomo. Nuestras pobres mujeres necesitarán muchos ensayos, muchas pruebas para emanciparse, para ser algo y tener una personalidad. ¡Y aun así! Ya ve usted, María es un ensayo de emancipación que fracasa (225-226).

Baroja, en el prólogo a La dama errante, señala que es enemigo del pasado por parecerle negro, sombrío y poco humano, pero asegura que siente «entusiasmo por el porvenir» (11). Sin duda el escritor creía en la emancipación de la mujer, aunque en la sociedad de su tiempo aún no fuera posible; por ello, en el «Epílogo feliz, casi triste», se ve la desilusión de Baroja ante este frustrado «caso de valor». 


\section{SACHA V. SAVAROF}

Sacha Savarof es la protagonista de El mundo es ansí (1912) ${ }^{14}$ segunda novela de la trilogía «Las ciudades». ${ }^{15}$ Este personaje está inspirado en Lydia Von Dehanoff, la mujer divorciada con la que se casó Paul Schmitz, el amigo suizo de Baroja. El escritor, que acudió como padrino a su boda en la iglesia ortodoxa de Biarritz, debió quedar impresionado ante la cultura de la joven rusa (Mainer, 2012: 193); lo que le sugirió la idea para este nuevo relato. Baroja sitúa la acción de la novela en un pasado reciente, concretamente en torno a los convulsos años que rodearon la Revolución rusa de 1905 y 1911. Entre los aspectos que merecen destacarse en la construcción de este personaje están, por un lado, la huella de Schopenhauer y, por otro, la técnica narrativa utilizada, que nos permite percibir el interior de Sacha, sus pensamientos más íntimos.

La estructura de la novela sigue el esquema típico usado por Baroja: un prólogo, tres partes - con una trama desarrollada de forma lineal- y un epílogo. En el prólogo, el narrador señala que, años después de su encuentro con Sacha: «conocí en casa de un profesor, en Ginebra, a una señora suiza, feminista, que había viajado mucho y vivido cerca de veinte años en Rusia» (20). Esta mujer que, casualmente, había sido la institutriz de Sacha, le contará la vida de la muchacha y le dejará «un paquete de cartas y unos apuntes que había escrito la rusa mientras estaba en España» (21). Con estas fuentes de información, el narrador va a componer la novela que dividirá en tres partes. La primera, escrita a partir de los datos que le dio madame Frossard, narra la infancia y juventud de la rusa hasta su divorcio en Moscú. La segunda, compuesta por diez capítulos, contiene la transcripción de nueve cartas enviadas por Sacha a su amiga Vera desde Florencia y un décimo capítulo escrito por el narrador. La tercera parte, relatada en primera persona por la protagonista, son fragmentos del diario íntimo que llevó en España mientras estuvo casada con Velasco. De la combinación de un narrador homodiegético en el prólogo, un narrador heterodiegético en la primera parte y en el epílogo, con las modalidades del testimonio (cartas y diario íntimo) en la segunda y tercera parte respectivamente, resulta una figura femenina redonda a la que accedemos desde diferentes puntos de vista. Por otra parte, el planteamiento de varias cuestiones de género sitúa a la novela en la vanguardia del pensamiento feminista.

\section{La sombra de Schopenhauer}

El mundo es ansí se publicó un año después de El árbol de la ciencia (1911) y esta protagonista barojiana, que tan poco interés ha suscitado entre la crítica, podría considerase como el equivalente femenino de Andrés Hurtado, dado que en su construcción cobra gran importancia la influencia espiritual de Schopenhauer. Ambos son hijos de padres calaveras y despóticos, y de madres víctimas: la de Andrés porque creyó «que sufrir era el destino de la mujer» (2008: 43) y la de Sacha porque la vida con un hombre tan impulsivo «la había desquiciado por completo» (29). Uno y otra leen novelas, estudian la carrera de Medicina y tienen ideales políticos opuestos a los de su época y progenitor. Andrés es republicano en un país monárquico y Sacha es revolucionaria en la Rusia del zar Nicolás II.

A diferencia de Andrés, Sacha experimenta una profunda transformación de carácter: «de una chiquilla díscola y voluntariosa se convirtió en una muchacha muy

\footnotetext{
${ }^{14}$ Todas las citas harán referencia a la siguiente edición: El mundo es ansí, Madrid, Caro Raggio, 1993. A partir de ahora se citará indicando solo el número de página.

${ }^{15}$ La trilogía «Las ciudades» está compuesta por César o nada (1910), El mundo es ansí (1912) y La sensualidad pervertida (1920).
} 
seria y formal»(29). El narrador explica en el capítulo segundo «De aristócrata a revolucionaria» las influencias que obraron el cambio. En primer lugar, creció sin conocer a su madre. Esta se había separado del general y vivía desde hacía años en Moscú en casa de una amiga. En segundo lugar, no recibió educación alguna hasta que a los catorce años su padre buscó a una institutriz suiza, Madame Frossard, una dama que se encargó de quitarle sus malas costumbres y le enseñó a leer, escribir y a hablar el francés correctamente. Finalmente, la lectura de unos libros que «sigilosamente»le había prestado un vecino que estudiaba en Alemania y la amistad con un joven médico revolucionario, la decidieron a hacerse médica. El padre, al que le parece un disparate que su hija quiera estudiar, contempla atónito cómo Sacha se prepara, y supera con éxito, los exámenes de ingreso a la Escuela de Medicina.

La juventud del Moscú de principios del XX tiene muy poco que ver con la del Madrid de finales del siglo XIX porque «España entera, y Madrid sobre todo, vivía en un ambiente de optimismo absurdo. Todo lo español era lo mejor» (2008: 39). En las Universidades rusas, en cambio, «el ambiente revolucionario era violento [...] Todos se encontraban en pleno misticismo humanitario: el vivir para los demás, el despreciar las comodidades y la riqueza, el sacrificarse por el pueblo eran entre ellos verdaderos dogmas» (31). Sacha, imbuida por un idealismo tolstiano, ayuda durante las vacaciones a los aldeanos «intentando despertar en ellos un deseo de mejoramiento y de perfección ética» (32) mas encuentra que «era imposible llevar una disciplina, una pauta moral a estos hombres acostumbrados a suplicar, a rezar, a emborracharse a esperarlo todo del milagro y de la casualidad»(32). A diferencia de Andrés, cuya lectura de Parerga y Paralipomena de Schopenhauer inducía a la no acción, Sacha, aunque horrorizada ante la brutalidad del pueblo, decide continuar con «su aspiración humanitaria y religiosa» (33). Su actitud voluntariosa recuerda uno de los primeros escritos de Baroja donde ya se advierte la influencia del gran pesimista alemán. En ese artículo se previene del sufrimiento que irremisiblemente acompaña al que se esfuerza por alcanzar un ideal: «El dolor es una fuerza impulsora del progreso. La Humanidad, como un caballo fogoso, corre en busca del ideal; el dolor es un acicate. Allá lejos están la dicha y la felicidad; pero a medida que se avanza, ¡cuántos dolores, cuántas tristezas!» (Baroja, 1899: 866).

Mas Sacha va a fracasar en la vida a causa del elemento romántico y una voluntad débil. En Ginebra, un joven filósofo arribista, la seduce con engaños para que se case con él: «La fue apartando poco a poco de sus estudios. [...] ¿Para qué averiguar tantas enfermedades y tantas miserias, cuando la vida sana y fuerte muestra su ubre llena de esencia vital y cuando la juventud sonríe? [...] Sacha le escuchaba. ¡Es tan fácil seguir al que promete la felicidad sin esfuerzo!» (62). Sin embargo, esa felicidad no llega. Al cabo de dos años de matrimonio, la pareja se odia y deciden divorciarse. Pocos meses después, cuando Sacha conozca a Velasco, observaremos otro ejemplo de su desorientada voluntad cuando se explique que aunque ella quería alejarse del pintor, este llegó a dominarla: «era un caso de sugestión, de captación de la voluntad. Velasco disponía, mandaba y Sacha dejaba hacer» (137).

A partir de la segunda parte, Sacha, al igual que otros héroes barojianos, oscilará «entre los periodos de sufrimiento [...] y los estados de abulia» (Inman Fox, 1963: 402): «Después de mi largo encierro en nuestra casa de campo me encuentro como una convaleciente, entregada a la vida vegetativa. Voy, ando de aquí para allí, con el alma vacía de emociones y de pensamientos. A veces tengo ganas de llorar» (105). En otra carta le dirá a su amiga Vera: «Vive una ya sin esperanza, y para simular la energía que no se tiene, para hacernos la ilusión de abarcar un radio de acción que no abarcamos, están el arte y la música y los libros, que son un poco de opio en nuestra vida sin vida» 
(109). La contemplación del arte, durante su estancia en Florencia, ostenta una virtud catártica: «Notas en mí inclinaciones artísticas. ¿Qué quieres que haga para no aburrirme? [...] Yo supongo, quizá me equivoque, que la mayoría de las mujeres que recorren estas salas de los museos se encuentran en situación parecida a la mía; supongo que tienen su pequeña o su gran tragedia y que buscan aquí la distracción o el consuelo...» (112-113). La experiencia del arte le permite liberarse momentáneamente del sufrimiento, y esta es una de las formas de atenuación de la concepción trágica de la vida según la teoría estética de Schopenhauer (López de Santa María, 2009: 21-22).

El pesimismo domina el final de la novela cuando una Sacha desalentada comprende que ella también ha sido una persona desagradecida: «La vida es esto; crueldad, ingratitud, inconsciencia, desdén de la fuerza por la debilidad, y así son los hombres y las mujeres, y así somos todos». Pero a diferencia de Andrés, Sacha abraza la filosofía de Schopenhauer porque a pesar del sufrimiento, tiene voluntad de vivir: ${ }^{16}$ «Sí; todo es violencia, todo es crueldad en la vida. ¿Y qué hacer? No se puede abstenerse de vivir, no se puede parar, hay que seguir marchando hasta el final» (213).

\section{Focalización y varias cuestiones de género}

El otro aspecto importante en la construcción de la rusa es que esta es percibida desde diferentes puntos de vista: el del narrador, ${ }^{17}$ el de los personajes y el suyo propio: a través de las cartas que dirige a su amiga Vera y los fragmentos de su diario íntimo. Lo interesante de este procedimiento es que, a partir de la segunda parte, Sacha deja de ser objeto de la subjetividad masculina. Por medio de la correspondencia epistolar con su amiga conoceremos además de sus impresiones sobre Florencia (ciudad a la que se retira tras su divorcio de Klein), sus reflexiones y pensamientos más íntimos. En sus apuntes sobre España, la narración autobiográfica nos permite adentrarnos en su psique y conocer «su difícil adaptación a una España violenta y arbitraria» (Mainer, 2012: 195).

Durante la novela se plantean cuestiones de género propias de la época como el papel de la mujer en relación al matrimonio y la maternidad, el divorcio o las que atañen a su educación. El narrador, por medio del estilo indirecto, hace hablar a otros personajes en el marco de su discurso: «Velasco, atropelladamente y sin hablar de Sacha, me dijo que las mujeres que se consideran civilizadas son el producto más antipático de la civilización, que la única misión de la mujer es estar en la cocina y cuidar de los niños, que él mandaría azotar en la calle a las sufragistas y feministas...» (19). Baroja utiliza a Velasco para mostrar el pensamiento que dominaba en la España de principios de siglo. ${ }^{18}$ Sacha abandona a su marido cuando descubre que este mantiene relaciones con una bailarina, Concha la Coquinera y, en el comentario del pintor, se ve también el resentimiento del hombre rechazado por su mujer. Baroja, en un artículo del 10 de enero de 1904 titulado «Adulterio y divorcio», publicado en la revista

16 «Nosotros mismos somos la voluntad de vivir: por eso tenemos que vivir, bien o mal» (Schopenhauer, 2005: 193).

${ }^{17}$ En el prólogo, este nos explica quién es y cómo conoció a Sacha Savarof, su retrato contiene, además de rasgos exteriores, vislumbres acerca de su carácter: «Era una mujer de veinticuatro a veinticinco años, rubia, muy blanca y sonrosada, los ojos claros e ingenuos, las cejas doradas, la nariz corta y los labios gruesos, que mostraban al sonreír una dentadura fuerte y brillante. No era una mujer bonita; pero sí de un gran atractivo; tenía aire de salvajismo, de candidez» (11).

${ }^{18}$ La subordinación de la mujer dentro del matrimonio estaba estipulada por ley: el artículo 57 del Código Civil de 1889 establecía que «el marido debe proteger a la mujer, y esta obedecer al marido». No fue hasta la Constitución de la Segunda República, cuando se estableció de forma legal la igualdad entre los sexos dentro y fuera del matrimonio (Nash, 1983: 20). 
Alma española, opina que la infidelidad es una falta que legitima el divorcio. Y en la primera parte de la novela, cuando se muestran las desavenencias en el primer matrimonio de Sacha, y su ruptura por medio del divorcio, el escritor está exponiendo una opción imposible de acuerdo a la legislación española vigente. Como ya había manifestado en el mismo artículo de Alma española (1904: 2): «Creo que el divorcio es hoy por hoy la única solución humana del conflicto; creo que España debe irse preparando para implantarlo». Sin embargo, no fue hasta la Segunda República, en 1932, cuando se aprobó la primera Ley de Divorcio, lo que sitúa el pensamiento de Baroja en un punto tremendamente avanzado para la época.

En la novela también se cuestiona la inferioridad intelectual de las mujeres. El joven médico Nicolás Leskov expresa su desacuerdo respecto a un modelo igualitario de educación entre hombres y mujeres, «es absurdo querer hacerlas sabias». Sacha, sin embargo, rebate a su amigo:

— ¿Por qué? ¿Por qué no hemos de ser sabias? — preguntaba Sacha un poco indignada. - ¿Qué sé yo! Me parece que no están ustedes organizadas para eso.

Sacha sacaba a relucir a su paisana Sofía Kovaleskaya, la célebre matemática profesora de Estocolmo, a la polaca madama Curie, a María Bashkitseff y a tantas otras conocidas en las ciencias y en las artes (48).

Baroja, al nombrar a esas figuras femeninas de la ciencia y el arte y «a tantas otras» señala su existencia y, con esto, contribuye a transmitir la idea de que con la formación adecuada, las mujeres también pueden colaborar, con su aportación, a la civilización. Sin embargo, estas mujeres son «un producto del Norte, de Inglaterra, de Noruega, de Rusia... Aquí en el Mediodía encontrará usted en la mujer la personalidad biológica, el carácter, el temperamento; nada más. Es el catolicismo, que ha ido produciendo su inferioridad»(191-192). Por medio de Aracelu, Baroja vuelve a criticar la educación española, como ya hiciera en La dama errante. El primo de Velasco le explica a Sacha que en España, las niñas únicamente aprenden a rezar y a hacer labores. El entorno y, sobre todo la familia, empuja a las muchachas a poner toda su inteligencia al servicio de «pescar» un marido y, una vez que lo consiguen, «su misión es estar en su casa» (191), sin hacer nada, sin ocuparse de nada. En 1918, cuando Pío Baroja escribió Las horas solitarias, parece que todo seguía igual, o peor, «he conocido señoras viejas que en su tiempo habían leído los libros de Chateaubriand, de Dumas y de Eugenio Sue. Hoy las biznietas de aquellas señoras no leen nada. [...] No se nota, y es cosa triste, que la mujer española evolucione hacia la cultura» (Baroja, 1982: 260).

Como ya observó Trueba (2003: 196): «Pío Baroja demuestra ya en los primeros años del siglo una especial sensibilidad hacia la problemática de la mujer, una conciencia del origen de su marginación, surgiendo además la oportunidad de su liberación». El escritor comprende que las mujeres españolas sin apenas educación y bajo la sombra del pecado no puedan desarrollar una personalidad. María Aracil y Sacha Savarof, sin embargo, brillan en la oscura y caótica Europa de principios del siglo XX. Para explicar por qué son diferentes recurre a sus biografías y se dedican los primeros capítulos de La dama errante y El mundo es ansí a explicar la infancia y la juventud de sus protagonistas. Estas muchachas independientes se han criado en un ambiente solitario, sin amigas, sin madre, sin religión. Reciben, además, una educación personalizada en la que se incluyen lenguas extranjeras y acceso a libros. Desde el principio queda claro que son personas muy capaces: María comienza a estudiar Química y «como era muy atenta y estudiosa, en poco tiempo llegó a saber manejar los aparatos, los ácidos, el soplete, los tubos de ensayo y consiguió analizar bien. Su padre le aseguró que si arreglaba un pequeño laboratorio tendría trabajo» (47). Sacha supera 
los dos primeros cursos de Medicina, sin embargo, en ambos casos, es el amor por un hombre lo que traba su evolución: María por seguir a su padre abandona Madrid y la posibilidad de un trabajo; Sacha, que cándidamente se deja engañar ante la palabrería de Klein, aparca sus estudios y sus ambiciones humanitarias.

Son mujeres valientes que se crecen en la adversidad. Cuando Sacha es encarcelada en Rusia no duda en confesarse «enemiga de la autocracia y entusiasta de la revolución» (33). Cuando María ve que su padre está en peligro, elige acompañarle en su huida. Asimismo, como observó Ortega (1916: 56) de otros personajes barojianos, estas figuras femeninas tampoco «echan raíces ni en una tierra ni en un oficio, sino que van rodando de pueblo en pueblo y de menester en menester empujad[a]s por sus fugaces corazones». Vemos a la joven burguesa madrileña cruzar, cual aventurera, España y Portugal, a veces a pie, otras a caballo, dormir en establos, en ermitas, viajar en barco, en tren, vivir y trabajar en Londres... Igualmente, la aristócrata rusa - de clara inspiración schopenhaueriana - pasa de la vida abandonada del campo a Moscú y, desde ahí, las circunstancias la llevarán a Ginebra, a Florencia y, arrastrada por Velasco, visitará las aldeas del Pirineo, San Sebastián, los pueblos de la Rioja, Madrid, Sevilla y el Puerto de Santa María en Cádiz.

En las tres novelas, Baroja trata temas de interés para la mujer como la educación, la amistad y la independencia femenina, asuntos, por entonces, poco comunes en literatura. Estas muchachas son presentadas como amigas de otras mujeres y las vemos estudiar, leer y vivir de manera independiente en Londres, Ginebra y Florencia. De ahí que como Casalduero (1972: 298), nos preguntemos por qué se ha hablado tanto «de la aversión de Baroja a las mujeres». Es innegable el espíritu feminista de La dama errante, La ciudad de la niebla y El mundo es ansí, y que ambas heroínas fracasen no se debe a una falta de valía sino a que, como lamenta el folletinista, la existencia «humilde y cómica» (Baroja, 1974: 127) de la sociedad moderna no produce dichos personajes.

\section{OBRAS CITADAS}

Azorín (1979) [1918], «El mundo es ansí», en Javier Martínez Palacio (ed.), Pío Baroja: El escritor y la crítica, Madrid, Taurus, 1979, pp. 409-412.

Baroja, Pío (1904, 10 de enero), «Adulterio y divorcio», Alma española, 10, p. 2, $\langle$ http://hemerotecadigital.bne.es/issue.vm?id=0003636242\&search=\&lang=es $>$.

Baroja, Pío (1951) [1899], «Sufrir y pensar», Obras completas de Pío Baroja, vol. VIII, Biblioteca Nueva, Madrid, pp. 865-866.

Baroja, Pío (1974) [1909], La ciudad de la niebla, Madrid, Caro Raggio.

Baroja, Pío (1982) [1918], Las horas solitarias, Madrid, Caro Raggio.

Baroja, Pío (1993) [1912], El mundo es ansí, Madrid, Caro Raggio.

Baroja, Pío (1995) [1908], La dama errante, Madrid, Caro Raggio.

Baroja, Pío (1997a) [1917], Juventud, egolatría, Madrid, Taurus.

Baroja, Pío (1997b) [1904], La busca, Madrid, Caro Raggio.

Baroja, Pío (2006), Desde la última vuelta del camino I, Barcelona, Tusquets.

Baroja, Pío (2008) [1911], El árbol de la ciencia, Madrid, Cátedra.

Baroja, Pío (2010) [1935], Vitrina pintoresca, Madrid, Ediciones 98.

Bergasa, Francisco (1973), Baroja, las mujeres y el sexo, Madrid, Editora Nacional.

Bieder, Maryellen (1992), «Woman and the Twentieth-Century Spanish Literary Canon. The Lady Vanishes», Anales de la literatura española contemporánea, 1/3, vol. 17, pp. 301324.

Campos, Jorge (1981), Introducción a Pío Baroja, Madrid, Alianza. 
Casalduero, Joaquín (1979) [1972], «Sentido y forma de La vida fantástica», en Javier Martínez Palacio (ed.), Pío Baroja: El escritor y la crítica, Madrid, Taurus, pp. 285-305.

Elizalde, Ignacio (1975), Personajes y temas barojianos, Bilbao, Universidad de Deusto.

Inman Fox, E. (1979), «Baroja y Schopenhauer: El árbol de la ciencia», en Javier Martínez Palacio (ed.), Pío Baroja: El escritor y la crítica, Madrid, Taurus, pp. 397-408.

Lázaro, Fernando y Vicente Tusón (1990) [1989], Literatura del siglo XX, Madrid, Anaya.

Lee Bretz, Mary (1979), La evolución novelística de Pío Baroja, Madrid, José Porrúa Turanzas.

López de Santa María, Pilar (2009), «Introducción», en Arthur Schopenhauer, El mundo como voluntad y representación I, Madrid, Trotta.

Mainer, José Carlos (2012), Pío Baroja, Madrid, Taurus.

Murphy, Katharine (2012), «The female subject in Pío Baroja», Modern Language Review, 107, pp. 1101-1122.

Nash, Mary (1983), Mujer, familia y trabajo en España (1875-1936), Barcelona, Anthropos.

Orts Agulló, Eva (2017), Personaje y espacio urbano en la narrativa de Pío Baroja, Vigo, Academia del Hispanismo.

Rivas, Ascensión (2017), Baroja (\& Yo). Mujeres barojianas, Pamplona, Ipso.

Trueba Mira, Virginia (2003), «Lulú: el extraño personaje de El árbol de la ciencia de Pío Baroja», Anales de la literatura española contemporánea, 1, vol. 28, pp.183-202.

Tusón, V. y Lázaro F. (1990), Literatura del siglo XX, Madrid, Anaya.

Umbral, Francisco (1999, 31 de octubre), «Baroja en el retiro», El Cultural, $\langle$ http://www.elcultural.com/revista/letras/Baroja-en-el-Retiro/14747>.

Woolf, Virginia (1929), Una habitación propia, Barcelona, Seix Barral, 1992. 